\title{
How many years of life could be saved if malaria were eliminated from a hyperendemic area of northern Ghana?
}

\author{
Ayaga A. Bawah
}

Population Council

Fred N. Binka

Follow this and additional works at: https://knowledgecommons.popcouncil.org/departments_sbsr-pgy

Part of the Demography, Population, and Ecology Commons, Family, Life Course, and Society Commons, Immunology and Infectious Disease Commons, International Public Health Commons, and the Medicine and Health Commons

How does access to this work benefit you? Let us know!

\section{Recommended Citation}

Bawah, Ayaga A. and Fred N. Binka. 2005. "How many years of life could be saved if malaria were eliminated from a hyperendemic area of northern Ghana?" Policy Research Division Working Paper no. 203. New York: Population Council. 


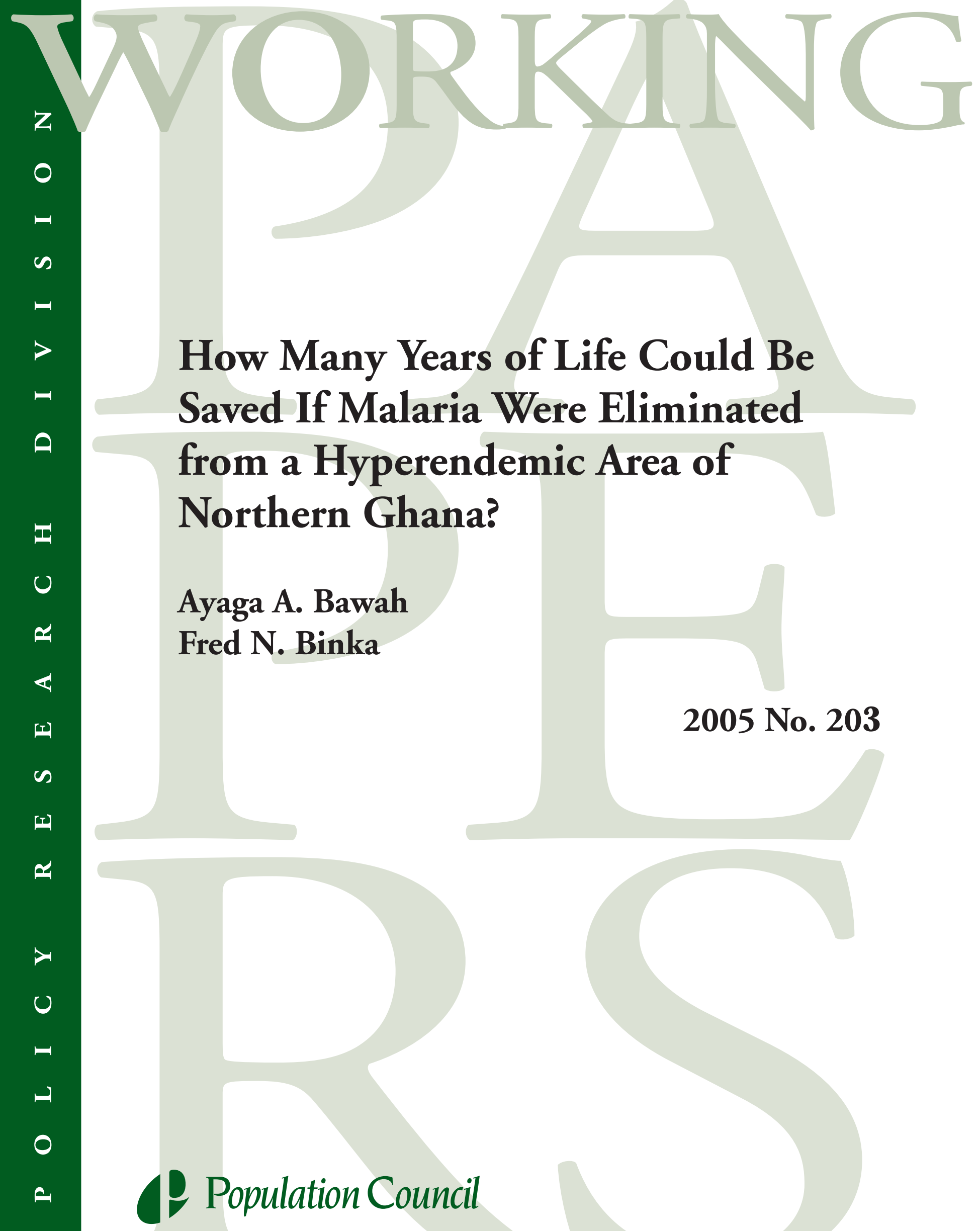




\section{(P) Population Council}

One Dag Hammarskjold Plaza

New York, New York 10017 USA

www.popcouncil.org

pubinfo@popcouncil.org

This material may not be reproduced without written permission from the authors. For a list of Policy Research Division Working Papers, including those that are currently available for downloading in PDF format, see www.popcouncil.org/publications/wp/prd/rdwplist.html.

ISSN: $1554-8538$

(C) 2005 The Population Council, Inc. 


\title{
How Many Years of Life Could Be Saved If Malaria Were Eliminated from a Hyperendemic Area of Northern Ghana?
}

\author{
Ayaga A. Bawah \\ Fred N. Binka
}

\begin{abstract}
Ayaga A. Bawah is Berelson Fellow, Population Council, New York. Fred N. Binka is Executive Director, The INDEPTH-Network, Post Office Box KD 213, Accra, Ghana.

Acknowledgments: The authors thank Tukufu Zuberi, Herbert Smith, and Etienne van de Walle, all of the University of Pennsylvania, for useful comments on earlier drafts. James Phillips of the Population Council provided both technical and substantive suggestions and advice on the final version. Finally, we acknowledge the staff of Navrongo Health Research Centre - the field staff for diligently collecting the data and the physicians for coding of causes of death.
\end{abstract}




\begin{abstract}
Malaria is endemic in about 90 countries of the world, half of which are in Africa. Little is known about the demographic impact of the disease, however. This paper uses demographic methods to examine the impact of mortality from malaria on overall mortality in a hyperendemic rural African setting. We use longitudinal demographic surveillance data from northern Ghana to estimate the total number of person-years that would have been saved had malaria been eliminated from the population in 1995, given the age- and cause-specific mortality conditions of the period and gains in life expectancy that are implied. Results suggest that as many as one-third of deaths in this population are attributable to malaria, depending on the age group under consideration, and that life expectancy at birth would likely increase by more than six years if malaria were eliminated as a cause of death.
\end{abstract}


For many tropical countries, malaria remains one of the most difficult health challenges. It is endemic in about 90 countries of the world, half of which are in Africa (WHO 1993). Malaria is estimated to affect between 300 and 500 million people worldwide every year, with 90 percent of all cases occurring in Africa (WHO 1998 and 2001). The disease is reported to be the leading cause of morbidity and mortality in Africa, accounting for about 20-30 percent of all infant deaths (Molyneaux 1985). Apart from the heavy toll in human lives, the medical costs and number of workdays lost to malaria in many African countries are great. ${ }^{1}$ In Ghana, malaria is reported to account for about 40 percent of all outpatient cases in hospitals and other health institutions (Ministry of Health 1999). According to the Ghanaian Ministry of Health, about 25 percent of all deaths among children below age five in the country are attributable to malaria. ${ }^{2}$

The social and economic costs of malaria in Africa are huge. The World Health Organization (WHO) estimates that malaria retards African economic growth by 1.3 percentage points per year (WHO 2000). The benefits of controlling the disease would, therefore, be great. According to WHO (2000), sub-Saharan Africa's gross domestic product (GDP) in 2000 might have been 32 percent greater had malaria been eliminated 35 years ago, an estimated increase of $\$ 100$ billion in the region's current GDP of $\$ 300$ billion.

Virtually all of the efforts to eliminate or control the disease in Africa to date have failed. Modest successes that were made in central and southern Africa in reducing the vector population by means of mass spraying in the late 1950s and 1960s have reversed in many cases. In countries of Asia and parts of Latin America where malaria was reportedly eradicated, the disease has reemerged as a major public health problem (Hamoudi and Sachs 1999). New strains of malaria-carrying parasites emerging in Africa and elsewhere are becoming resistant to known and common forms of treatment. The emergence of these drug-resistant strains poses a further threat to efforts aimed at curtailing the disease not only in Africa, but globally.

Although Africa is known to have the highest level of malaria endemicity in the world, investigators have paid little attention to the measurement of the demographic impact of the disease in the region. The present analysis is aimed at bridging this void by estimating the total number of person-years that might be saved if malaria were eliminated from the population. We employ cause-of-death data to estimate malaria and all-cause mortality using multiple-decrement life tables. Assuming a hypothetical situation in which malaria is eliminated, we estimate the expected reduced mortality that could result and the consequent increases in life expectancy. This analysis complements the paper by Binka et al. (1997), which examined the economic impact of malaria for the same population.

\section{STUDY SITE}

This paper is based on data collected at the Navrongo Health Research Centre in the Kassena-Nankana district of northern Ghana, within the Guinea Savannah woodland zone of northern Ghana, where semiarid conditions arise from a short rainy season with an average annual rainfall of $850-950 \mathrm{~mm}$ (33-37 inches) followed by a dry and hot 
season. Mean monthly temperatures are in the range of $20-40^{\circ}$ centigrade $\left(68^{\circ}-104^{\circ}\right.$ Fahrenheit). Although subsistence farming is the mainstay of the economy, crop cultivation is limited to the rainy season. Limited irrigation farming is practiced during the dry season, facilitated by the Tono Irrigation Project. Low agricultural productivity, geographic isolation, and pervasive poverty typify the circumstances in Ghana's northern regions (Navrongo Health Research Centre 1999).

Both fertility and mortality have declined in the district, although levels remain high (Navrongo Health Research Centre 1999). The total fertility rate (TFR) was in excess of five children per woman of reproductive age at baseline in 1993, whereas infant and child mortality rates were reported to be 116 and 22 deaths per 1,000 live births, respectively (Binka et al. 1999). The high levels of childhood mortality are the result of infectious and parasitic diseases such as malaria and of diseases related to diarrhea and respiratory infections (Binka et al. 1994). Most children suffer from malnutrition, exacerbating the mortality impact of disease. The health infrastructure in the district is poor compared with many other parts of Ghana. Only one hospital serves the district; it is located in Navrongo town and therefore is inaccessible to those living in scattered villages, who represent about 90 percent of the district's population. Although a few health centers and posts exist in different parts of the district, these are inadequately staffed and provide no services beyond primary care. Consequently, the majority of the population relies on "self-medication" or the use of traditional medicine. As a result of the low use of health-care facilities in the district, 82 percent of all deaths of children and 89 percent of adult deaths in 1995 occurred at home.

\section{DATA}

We employ cause-of-death data gathered at the Navrongo Health Research Centre (NHRC) through the Navrongo Demographic Surveillance System (NDSS) (Binka et al. 1999). Since 1993, the NDSS has been monitoring demographic events-pregnancies, births, deaths, and migrations into and out of Kassena-Nankana District. Currently, the total population under surveillance is about 143,000 (Bawah et al. 2004). This paper uses data for 1995 and restricts the analysis to the rural segment of the population, which in 1995 was estimated at 126,000 . We excluded the urban population because it was not integrated into the NDSS until the end of 1995. Also, at the time of this analysis the 1995 data comprised the only complete data set available from verbal autopsies. ${ }^{3}$ Data for a total of 2,193 deaths are used for the analysis.

All deaths recorded in the NDSS are followed up with a verbal autopsy to ascertain the possible cause of death. Verbal autopsy involves interviewing relatives or caregivers who were closely associated with the deceased during the period leading to her or his death. To evaluate health-program interventions, this method has been used extensively in Africa and other parts of the developing world to ascertain information about causes of death, especially the deaths of children (Garenne and Fontaine 1986; Alonso et al. 1987; Greenwood et al. 1987; Boerma and Mati 1989; Snow et al. 1992; Ghana VAST Study Team 1993; Oosterbaan 1995). Three independent physicians code the data, and, for each death, a minimum of two must agree for a particular cause to be 
assigned as the most probable cause of death. Through this procedure, about 17 different specific causes of deaths were identified among children and 22 causes identified among adults in the NDSS (see Figures 1 and 2).

As the two figures show, nearly a third of all childhood deaths and about a fifth of adult deaths are attributable to malaria in this setting. Although the major causes of childhood deaths differ from the adult deaths, malaria tends to dominate as the reported main cause of death for both children and adults, if unknown causes of death are excluded. A large proportion of causes of death are reported as unknown, indicating either that a number of the interviews did not elicit adequate information from the respondents to allow the physicians to make informed diagnoses or that the three physicians differed in their assessment of the probable cause of death in many cases (which might be the result of their being given poor information). Doctors' disagreement is more likely to occur in cases of adult deaths; more than 35 percent of these are coded as unknown, consistent with the widely held view that verbal autopsies are not as reliable for capturing causes of adult deaths as they are for capturing those of childhood deaths (Kalter 1992). The data presented here have been evaluated thoroughly and found to be of good quality (Bawah 2002).

\section{ESTIMATION Procedure}

Direct estimation of the impact of malaria on mortality would be possible if clinical records were available for deaths from the disease for the entire population or if epidemic morbidity and mortality were precisely assessed (Bradley 1996). Neither of these approaches is possible in most African settings because clinical records concerning the disease are nonexistent for most episodes of illness and because the hyperendemicity of malaria maintains its high and stable cycles of morbidity from year to year. Therefore, we evaluate malaria's effect on overall mortality by estimating the number of personyears that could be saved assuming the disease was eliminated as a major cause of death in this population, and we estimate its impact using multiple-decrement and associated single-decrement life table techniques. This approach allows us to evaluate the extent to which mortality could be reduced if malaria were eliminated from the population and enables us to decompose by age the decrease in mortality as it would be reflected in increased life expectancy. In this way, we are able to determine the ages for which a decline in mortality from malaria would make the greatest impact on survival.

We employed multiple-decrement life tables and associated multiple-decrement life-table techniques (Keyfitz 1985; Preston et al. 2001) to estimate mortality from malaria and its impact on overall mortality. These methods rely on estimating the net effect of competing risks from different causes, that is, from malaria versus from other causes, under the assumption that different causes operate independently of each other (Keyfitz 1985; Preston et al. 2001). Although the assumption of independence may be unrealistic in some situations, determining the nature of dependencies is often difficult, especially in the case of malaria, which can manifest a number of symptoms. As Preston (1976) noted, the assumption of independence often is imposed on the analyst because the rules of the International Classification of Diseases stipulate that, "while several 
causes of death can be listed on a death certificate, each death must be attributed to one cause in the primary tabulations" (Murray and Lopez 1996). Because this rule requires assigning a primary cause of death, most medical practitioners tend to list only the cause that they think is responsible for the person's death. Therefore, we treat the causes of death as being independent of each other. For a detailed exposition of the methodology used here, see Appendix 1.

\section{DeCOMPOSITION BY AgE}

To ascertain the age groups likely to contribute most to the total difference in life expectancy at birth as a result of the elimination of malaria, we decomposed the total difference in life expectancy into specific age groups, using the procedure proposed by Arriaga (1984). This approach permits estimation of specific reductions in mortality due to the disease by age group and consequent increases in life expectancy in the population.

$$
{ }_{n} \Delta_{x}=\frac{l_{x}^{\text {all }}}{l_{0}^{\text {all }}} \cdot\left(\frac{{ }_{n} L_{x}^{- \text {malaria }}}{l_{x}^{- \text {malaria }}}-\frac{{ }_{n} L_{x}{ }^{\text {all }}}{l_{x}^{\text {all }}}\right)+\frac{T_{x+n}{ }^{- \text {malaria }}}{l_{0}^{\text {all }}} \cdot\left(\frac{l_{x}^{\text {all }}}{l_{x}^{- \text {malaria }}}-\frac{l_{x+n}^{\text {all }}}{l_{x+n}{ }^{- \text {malaria }}}\right)
$$

where the superscripts all and -malaria indicate, respectively, with and without malaria. The first term at the right side of the equation refers to the direct effect of a change in mortality rates between ages $x$ and $x+n$, whereas the second term refers to the sum of both the indirect and interaction effects of contributions resulting from the number of person-years to be added because of additional survivors at age $x+n$ exposed to the new mortality conditions (Preston et al. 2001). The equation used for the open-ended interval is as follows:

$$
{ }_{\infty} \Delta_{x}=\frac{l_{x}^{\text {all }}}{l_{0}^{\text {all }}} \cdot\left(\frac{T_{x}^{\text {-malaria }}}{l_{x}^{\text {-malaria }}}-\frac{T_{x}^{\text {all }}}{l_{x}^{\text {all }}}\right) .
$$

Thus, the change in life expectancy $\left(\ell_{0}^{o(- \text { malaria })}-\ell_{0}^{o(\text { all })}=\sum_{x}{ }_{n} \Delta_{x}\right)$ can be decomposed according to the contribution of the different age groups.

\section{DATA Limitations}

Some of the deaths for which we have data have causes coded as "unknown." In other studies, such deaths often have been considered as a separate category, and "unknown" has been designated as one of the causes. Because our interest is to estimate the impact of mortality resulting from malaria, treating the unknown deaths as a separate category implicitly assumes that they are the result of a competing cause. Some of the deaths in this category, however, may indeed be the result of malaria. In response to this dilemma, we first treated them as a separate category by adding them to the rest of the causes other than malaria and then estimated the impact of deaths from malaria on overall mortality. 
Subsequently, we assumed that some of the deaths from unknown causes could have resulted from malaria, and we allocated them proportionately among the known causes and reran the analysis to see the magnitude of their effect on possible changes in the mortality rates. We adopted this approach because treating the unknowns as a competing cause of death may produce a conservative estimate if some of the deaths resulted from malaria. Allocating them among known causes, however, may increase the number of deaths calculated as resulting from malaria and its mortality impact. Estimating the impact of the disease before and after the reallocation of the unknown deaths approximates the possible range in the magnitude of mortality due to malaria in the study population.

\section{RESULTS}

Of the 2,193 deaths recorded for 1995, 512 were diagnosed as resulting from malaria, representing close to one-fourth (23 percent) of all deaths in the KassenaNankana district. Malaria is broadly defined to include all febrile illnesses. ${ }^{4}$ The overall crude mortality rate for the district is estimated at 17.4 deaths per 1,000 and the crude mortality rate for malaria is about 4.1 deaths per 1,000. Although these composite estimates give a fair idea about the level of mortality, both from all causes and for malaria in particular, they do not tell us anything about the age pattern of mortality. A life table representing these deaths by age is presented in Table 1. As the table shows, the age pattern of mortality for malaria is similar to that for all causes. Mortality is high at the younger and older ages, showing the typical pattern of mortality in developing countries (see also Figure 3). Specifically, the results show an estimated infant mortality rate $\left({ }_{1} m_{0}\right)$ of 0.092 and child mortality rate $\left({ }_{4} m_{1}\right)$ of 0.026 . The corresponding estimated probabilities of dying before age one $\left({ }_{1} q_{0}\right)$ and between ages one and four for those who survive to age one $\left({ }_{4} q_{1}\right)$ are 0.087 and 0.097 , respectively. These estimates translate into a life expectancy at birth of 48.8 years, a pattern characteristic of a high-mortality population.

In Figure 3, the observed age-specific mortality rates from Navrongo are shown for all causes combined and for malaria and are compared with age-specific mortality rates for infectious diseases from Preston's 2001 national populations. The age pattern of mortality suggested by the Navrongo data compares closely with Preston's estimates, which he describes as representing the typical pattern of mortality for populations in high-mortality settings where life expectancy is in the range of 45-54 years.

To evaluate the impact of mortality from malaria on overall mortality, we isolated data for those deaths due to malaria that were diagnosed by means of verbal autopsy interviews and estimated a multiple-decrement life table in order to answer the question, "How many newborns may eventually die from malaria if the age-specific mortality conditions of 1995 prevail?" Starting with a cohort of 100,000 new births, we estimated that 22,250 of them may eventually die from malaria by the time they reach age 75 , assuming that the age-specific mortality conditions of 1995 prevailed throughout their life course. This finding means that given the cause-specific mortality conditions of 1995 , 
more than 22 percent of all newborn children may eventually die from malaria by the time they reach age 75 , a very high mortality level.

In Table 2, we show the expected gains in life expectancy if malaria were eliminated. The table shows that overall, the probability of surviving to age 75 is likely to increase in the absence of malaria from 0.18 to 0.27 , with a corresponding increase in life expectancy at birth from 48.8 to 54.9 years, a probable gain of about 6.1 years. Figure 4 displays life expectancy at each age when all causes of death are combined and the corresponding life expectancy at each age in the absence of malaria. The figure clearly shows an increase in life expectancy at every age in the absence of malaria.

Although life expectancy is shown to have increased at every age in the absence of malaria, the increase is more pronounced at the early ages of life than at other ages, as depicted in Figure 4. Results from a decomposition of the gains in life expectancy at birth discussed below show clearly that the younger age groups - those younger than fiveaccount for the greatest gains in life expectancy at birth. This result is expected because most deaths (36 percent) occur in this age group and most of these deaths ( 27 percent) are caused by malaria. Figure 5 portrays the number of those surviving to each age $\left(l_{x}\right)$ when all causes of death are combined and in the hypothetical situation where malaria is assumed to have been eliminated as a cause of death in the population. Thus, starting with a cohort of 100,000 new births, the figure shows that many more people would be likely to survive at every age if malaria were eradicated from the population (see also Table 2).

Although the estimates presented clearly demonstrate the potential improvements in life expectancy at birth if malaria were eliminated, they do not clarify which age groups potentially are likely to contribute most to this improvement. To answer this question, we decomposed the total change in life expectancy at birth (6.1 years) by age. Results of this decomposition are presented in Table 3. As the decomposition results show, the age groups that likely would contribute most to an increase in life expectancy if mortality from malaria were eliminated are children in the one-year and one-to-four-year age groups). The contribution of under-five mortality to the total change in life expectancy at birth is about 45 percent.

Although the results shown in Table 3 demonstrate a substantial impact of mortality from malaria, we may have underestimated the impact of the disease because a large proportion of the deaths that are diagnosed as "unknown" may, in fact, be caused by malaria. The distribution of deaths from unknown causes has a shape similar to those of infectious and parasitic diseases, among which malaria is the main cause of death (see Appendix Figure A1). In view of this circumstance, we reallocated proportionally the unknown deaths among the known causes and re-estimated the impact of mortality from malaria (Appendix Tables A1 and A2 show the distribution of deaths before and after the reallocation). In Appendix Tables A3-A5, we present multiple-decrement and associatedmultiple-decrement life tables and results of the decomposition of life expectancy at birth showing the effect of mortality from malaria after the reallocation of deaths from unknown causes. 
When we allocated the deaths from unknown causes among the major categories of known causes and re-estimated the impact of mortality from malaria, the estimated probability of surviving to age 75 increased further, to 0.33 , assuming that malaria was eliminated as a major cause of death in the population. The corresponding life expectancy at birth is also expected to increase further to 58.2 years from 48.8 years, representing an estimated probable gain of 9.4 years. (Without the allocation, the estimated gain in life expectancy is 6.1 years as noted above). Thus, after the allocation, there is an estimated additional gain of 3.3 years from the initial estimate of 54.9 to 58.2 years. Appendix Figure A2 portrays the decomposition of the respective expected increases in life expectancy before and after the allocation of deaths from unknown causes. As anticipated, the greatest contribution to the potential increase in life expectancy at birth if malaria were eliminated is likely to come from children younger than one and those between one and four years old.

\section{DisCUSSION AND CONCLUSION}

Little systematic attention has been directed to researching the demographic impact of malaria in Africa, although the disease remains the leading cause of childhood mortality and is implicated in mortality risks at all ages. Because malaria is most severe in infancy and childhood, much of the emphasis of clinical researchers and epidemiologists tends to center on malaria occurring at these ages. Evidence from Navrongo demonstrates that the disease affects all ages, although its mortality impact diminishes with age owing to an increase in immunity that occurs over time. Findings from Navrongo support the assessment of the Multilateral Initiative on Malaria (MIM) that the burden of malaria has been grossly underestimated in Africa (Breman et al. 2001). The latter conclusions, however, are based on clinical and epidemiological data that lack specificity for the age pattern of mortality from the disease.

This paper documents the age pattern of mortality from the disease and its consequential shortening of life. Our results show that between about one-fourth and onethird of all deaths in this population are attributable to malaria, depending on the age group considered. Striking differences exist by age: mortality from malaria is highest in childhood - about 45 percent of the deaths due to malaria occur to children. Overall, the results suggest that if malaria were eliminated from this population, life expectancy at birth could be expected to increase by more than six years, constituting a substantial achievement.

Contrary to the conventional view that the prevalence of mortality from malaria is low at older ages, results from Navrongo suggest that it is high, a finding indicating that immunity to the disease is compromised as age progresses. Older people tend to have lower resistance to diseases in general compared with young adults, especially in Africa where malnutrition is high. Malaria among the elderly may also increase their vulnerability to other diseases.

The effect of mortality from malaria may have been underestimated where verbal autopsy data are used, because not all deaths that are recorded for the surveillance project 
are followed through with successful verbal autopsy interviews. Even in cases of deaths for which interviews were conducted, the fraction coded as "unknown" is high. If malaria deaths are assumed to represent a large proportion of the cases categorized as unknown in the reported cases, it is possible that we have underestimated malaria mortality. For example, if the deaths from unknown causes are allocated among the other categories, the expected gain in life expectancy at birth increases by nine years, implying three additional years gained beyond the six years achieved by eliminating malaria.

Our analysis suggests that the malaria epidemic represents one of the major challenges facing Africa medically, socially, and economically. Results attest to the need for a concerted effort by epidemiologists, parasitologists, entomologists, and social scientists to build scientific understanding of this preventable yet deadly disease that has long plagued large portions of the world's population, especially in Africa.

\section{NoTES}

1 For example, in 1993 the World Bank ranked malaria as the leading cause of disability-adjusted life years (DALYs) in Africa, with an estimated loss of 35 million future life-years from disability and premature deaths due to the disease (WHO, cited in Binka et al. 1997). In a malaria summit between African heads of states and the WHO Roll Back Malaria (RBM) team held in Abuja, Nigeria, concern was expressed by the African heads of states about the enormous burden of the disease on the continent, in terms of its toll on human life and the social and economic costs of the disease to their countries. Consequently, the heads of states pledged to work together with the RBM team to reduce the impact of the disease (WHO 2000).

2 Studies conducted in the Kassena-Nankana district of northern Ghana have also demonstrated that malaria is the major killer of both children and adults in the area (Ghana VAST Study Team 1993; Binka et al. 1994 and 1996; Binka 1997). Demonstrating the impact of impregnated bed nets as a strategy for malaria control in Kassena-Nankana, Binka et al. (1997) showed that about 16,800 child-years were protected and 74 deaths of children averted at an estimated cost of US $\$ 8.80$ per child-year protected and US $\$ 2,003$ per death averted. The estimated cost per discounted healthy life-years gained was US $\$ 73.50$.

3 Verbal autopsy is a tool for ascertaining causes of death in settings where no vital registrations are maintained and where most deaths occur outside of a health institution (Greenwood et al. 1987; Snow and Marsh 1992; Ghana VAST Study Team 1993).

4 The majority of patients presenting with febrile symptoms at the War Memorial Hospital in Navrongo where malaria tests are conducted have tested positive for malaria. 


\section{REFERENCES}

Alonso, P.L. et al. 1987. "The accuracy of the clinical histories given by mothers of sick African children." Unpublished.

Arriaga, E. 1984. "Measuring and explaining the change in life expectancy." Demography 21(1): 83-96.

Bawah, A.A. 2002. Health, Well-being and Mortality in Africa. Graduate Group in Demography, University of Pennsylvania. Doctoral dissertation.

Bawah, A.A. et al. 2004. "The Navrongo Demographic Surveillance System: Ten years of demographic monitoring levels and trends." Unpublished.

Binka, F.N. 1997. Impact and Determinants of Permethrin Impregnated Bed Nets on Child Mortality in Northern Ghana. Inaugural Dissertation. Basel: BaslerSchnelldruck-Bernhard Schlattmann.

Binka F.N. et al. 1994. "Patterns of malaria morbidity and mortality in children in Northern Ghana." Transactions of The Royal Society of Tropical Medicine and Hygiene. 88(4): 381-385.

Binka et al. 1996. "Impact of permethrin impregnated bed nets on child mortality in the Kassena-Nankana District, Ghana: A randomized controlled trial." Tropical Medicine and International Health 1(2): 147-154.

Binka et al. 1999. "Assessing population dynamics in a rural African society: Findings from the Navrongo Demographic Surveillance System." Journal of Biosocial Science 31(3): 375-391.

Binka, F.N., O.A. Mensah, and A. Mills. 1997. "The cost-effectiveness of permethrin impregnated bednets in preventing child mortality in the Kassena-Nankana District of Northern Ghana." Health Policy 41(3): 229-239.

Boerma, J.T and J.K. Mati. 1989. "Identifying maternal mortality through networking: Results from coastal Kenya." Studies in Family Planning 20(5): 245-253.

Bradley, T. 1996. Special Study Module Project Report. Department of Microbiology and Immunology, University of Leicester, UK. <http://www.msb.le.ac.uk/224/Bradley/ History.html>. Accessed February 2002.

Breman, J.G., A. Egan, and G.T. Kleusch. 2001. "The intolerable burden of malaria: A new look at the numbers." American Journal of Tropical Medicine \& Hygiene 64(1-2 supplement): iv-vii. 
Chiang, C.L. 1968. An Introduction to Stochastic Processes in Biostatistics. New York: John Wiley \& Sons.

Coale, A. and P. Demeny. 1983. Regional Model Life Tables and Stable Populations. New York: Academy Press

Garenne M. and O. Fontaine. 1986. "Assessing probable causes of death using standardized questionnaires: A study in rural Senegal." In Measurement and Analysis of Mortality. Eds. J. Vallain, S. D'Souza, and A. Palloni. Proceedings of the International Union for the Scientific Study of Population (IUSSP) seminar held in Siena, 7-10 July 1986. Oxford: Clarendon Press. Pp. 123-142.

Ghana Vitamin A Supplementation Trials (VAST) Study Team. 1993. "Vitamin A supplementation in northern Ghana: Effects on clinical attendance, hospital admissions, and child mortality." Lancet 342(8,862): 7-12.

Greenwood, B.M. et al. 1987. "Deaths in infancy and early childhood in a wellvaccinated rural West African population." Annals of Tropical Paediatrics 7(2): 91-99.

Hamoudi, A. and J.D. Sachs. 1999. "The Changing Distribution of Malaria: A review." Center for International Development Working Paper No. 2. Cambridge, MA: Harvard University.

Kalter, H. 1992. "The validation of interviews for estimating morbidity." Health Policy Planning 7(1): 30-39.

Keyfitz, N. 1985. Applied Mathematical Demography. Springer Texts in Statistics. New York: Springer-Verlag.

Ministry of Health (Ghana). 1999. "Malaria dominates OPD cases." Report from seminar proceedings organized by The World Health Organization, reported by The Independent through Africa News. $<\mathrm{http}: / /$ www.malaria.org $>$. Accessed February 2002.

Molyneaux, L. 1985. "The impact of parasitic diseases and their control, with emphasis on malaria and Africa." In Health Policy, Social Policy and Mortality Prospects, J. Vallin and A. Lopez (eds). Liège: Ordina Editions. Pp. 13-44.

Navrongo Health Research Centre. 1999. Final Report to the Population Council Africa Operations Research and Technical Assistance Project. Accra: Ministry of Health, Republic of Ghana.

Oosterbaan, M.M. 1995. “Guinea Bissau: Maternal mortality assessment.” World Health Statistics Quarterly 48(1): 34-38. 
Preston, S.H. 1976. Mortality Patterns in National Populations. New York: Academic Press.

Preston, S.H., P. Heuveline, and M. Guillot. 2001. Demography: Measuring and Modeling Population Processes, Oxford: Blackwell Publishers.

Snow, R.W. and K. Marsh. 1992. "How useful are verbal autopsies to estimate childhood causes of death?" Health Policy and Planning 7(1): 21-29.

Snow, R.W., J.R. Armstrong, D. Forster, M.T. Winstanley, V.M. Marsh, C.R. Newton, C. Waruiru, I. Mwangi, P.A. Winstanley, and K. Marsh. 1992. "Childhood deaths in Africa: Uses and limitations of verbal autopsies." Lancet 340(8,815): 351-355.

World Health Organization (WHO). 1993. Implementation of the Global Malaria Control Strategy. Report of a WHO study group on the implementation of the global plan of action for malaria control 1993-2000. Geneva: WHO.

— 1998. Fact sheets. $<$ http://www.who.int/inf-fs/en/fact094.html >. Accessed February 2002.

_ 2000. "Economic costs of malaria are many times higher than previously estimated." Press release: African Summit on Roll Back Malaria, Abuja, Nigeria. WHO/28. $<$ http://www.malaria.org $>$. Accessed February 2002.

—. 2001. WHO Malaria Database. <http://www.wehi.edu.au/MalDBwww/who.html>. Accessed February 2002. 
Table 1 A general and a multiple-decrement life table for Kassena-Nankana District, Ghana, 1995

\begin{tabular}{|c|c|c|c|c|c|c|c|c|c|c|c|c|c|c|c|c|}
\hline Age $x$ & $\begin{array}{r}\text { Person- } \\
\text { years } \\
\end{array}$ & $\mathbf{D}^{\text {All }}$ & $\mathbf{D}^{\text {malaria }}$ & $\mathrm{n}^{\mathbf{a}_{\mathbf{x}}}$ & ${ }_{n} \mathbf{m}_{\mathbf{x}}$ & ${ }_{n} \mathbf{q}_{x}$ & ${ }_{n} \mathbf{p}_{x}$ & $\mathbf{l}_{\mathbf{x}}$ & ${ }_{n} d_{x}$ & ${ }_{n} \mathbf{l}_{\mathbf{x}}$ & $\mathbf{T}_{\mathbf{x}}$ & $\mathbf{e}_{\mathbf{x}}$ & ${ }_{n} \mathbf{q}_{\mathbf{x}}{ }^{\text {malaria }}$ & ${ }_{n} \mathbf{d}_{\mathbf{x}}{ }^{\text {malaria }}$ & $\mathbf{l}_{\mathrm{x}}{ }^{\text {malaria }}$ & ${ }_{n} \mathbf{m}_{\mathbf{x}}{ }^{\text {malaria }}$ \\
\hline 0 & 4,076 & 374 & 77 & 0.340 & 0.0917 & 0.0865 & 0.9135 & 100,000 & 8,651 & 94,290 & $4,875,779$ & 48.8 & 0.0178 & 1,781 & 22,250 & 0.0189 \\
\hline $1-4$ & 15,001 & 384 & 130 & 1.874 & 0.0256 & 0.0971 & 0.9029 & 91,349 & 8,871 & 346,540 & $4,781,489$ & 52.3 & 0.0329 & 3,003 & 20,469 & 0.0087 \\
\hline $5-9$ & 19,106 & 94 & 20 & 2.490 & 0.0049 & 0.0243 & 0.9757 & 82,478 & 2,004 & 407,361 & $4,434,949$ & 53.8 & 0.0052 & 426 & 17,466 & 0.0010 \\
\hline $10-14$ & 16,920 & 57 & 15 & 2.347 & 0.0034 & 0.0167 & 0.9833 & 80,474 & 1,344 & 398,807 & $4,027,587$ & 50.0 & 0.0044 & 354 & 17,040 & 0.0009 \\
\hline $15-19$ & 12,004 & 31 & 10 & 2.585 & 0.0026 & 0.0128 & 0.9872 & 79,131 & 1,015 & 393,202 & $3,628,780$ & 45.9 & 0.0041 & 328 & 16,686 & 0.0008 \\
\hline $20-24$ & 7,254 & 33 & 4 & 2.721 & 0.0045 & 0.0225 & 0.9775 & 78,115 & 1,759 & 386,570 & $3,235,578$ & 41.4 & 0.0027 & 213 & 16,358 & 0.0006 \\
\hline $25-29$ & 7,015 & 54 & 10 & 2.568 & 0.0077 & 0.0378 & 0.9622 & 76,357 & 2,885 & 374,768 & $2,849,008$ & 37.3 & 0.0070 & 534 & 16,145 & 0.0014 \\
\hline $30-34$ & 6,672 & 50 & 6 & 2.553 & 0.0075 & 0.0368 & 0.9632 & 73,472 & 2,703 & 360,744 & $2,474,240$ & 33.7 & 0.0044 & 324 & 15,611 & 0.0009 \\
\hline $35-39$ & 7,052 & 73 & 13 & 2.569 & 0.0104 & 0.0505 & 0.9495 & 70,768 & 3,573 & 345,155 & $2,113,496$ & 29.9 & 0.0090 & 636 & 15,287 & 0.0018 \\
\hline $40-44$ & 5,468 & 65 & 11 & 2.580 & 0.0119 & 0.0578 & 0.9422 & 67,196 & 3,882 & 326,585 & $1,768,341$ & 26.3 & 0.0098 & 657 & 14,650 & 0.0020 \\
\hline $45-49$ & 5,878 & 98 & 19 & 2.563 & 0.0167 & 0.0801 & 0.9199 & 63,313 & 5,072 & 304,204 & $1,441,756$ & 22.8 & 0.0155 & 983 & 13,993 & 0.0032 \\
\hline $50-54$ & 5,766 & 112 & 17 & 2.622 & 0.0194 & 0.0928 & 0.9072 & 58,241 & 5,406 & 278,352 & $1,137,552$ & 19.5 & 0.0141 & 821 & 13,010 & 0.0029 \\
\hline $55-59$ & 4,962 & 168 & 47 & 2.429 & 0.0339 & 0.1557 & 0.8443 & 52,835 & 8,228 & 243,024 & 859,200 & 16.3 & 0.0436 & 2,302 & 12,189 & 0.0095 \\
\hline $60-64$ & 3,207 & 123 & 20 & 2.420 & 0.0383 & 0.1745 & 0.8255 & 44,607 & 7,783 & 202,955 & 616,175 & 13.8 & 0.0284 & 1,266 & 9,887 & 0.0062 \\
\hline $65-69$ & 2,633 & 173 & 46 & 2.363 & 0.0657 & 0.2800 & 0.7200 & 36,824 & 10,310 & 156,935 & 413,221 & 11.2 & 0.0744 & 2,741 & 8,622 & 0.0175 \\
\hline $70-74$ & 1,423 & 103 & 20 & 2.350 & 0.0724 & 0.3036 & 0.6964 & 26,514 & 8,050 & 111,232 & 256,286 & 9.7 & 0.0590 & 1,563 & 5,880 & 0.0141 \\
\hline $75+$ & 1,579 & 201 & 47 & 7.856 & 0.1273 & 1.0000 & 0.0000 & 18,464 & 18,464 & 145,054 & 145,054 & 7.9 & 0.2338 & 4,317 & 4,317 & 0.0298 \\
\hline Total & 126,018 & 2,193 & 512 & - & - & - & - & - & - & - & - & - & - & 22,250 & - & - \\
\hline
\end{tabular}

$-=$ Not applicable.

${ }_{n} \mathrm{a}_{\mathrm{x}}=$ Average number of person-years lived in the interval by those who have died in the interval.

${ }_{n} m_{x}=$ Mortality rate for people in age group $x$ to $x+n$.

${ }_{n} q_{x}=$ Probability of dying between ages $x$ and $x+n$.

${ }_{n} p_{x}=$ Probability of surviving between ages $x$ and $x+n$.

$1_{\mathrm{x}}=$ Number surviving at each age.

${ }_{n} d_{x}=$ Number of deaths between ages $x$ and $x+n$.

${ }_{n} l_{x}=$ Person-years lived between ages $x$ and $x+n$.

$\mathrm{T}_{\mathrm{x}}=$ Person-years lived beyond age $\mathrm{x}$.

$\mathrm{e}_{\mathrm{x}}=$ Life expectancy at age $\mathrm{x}$. 
Table 2 Associated single-decrement life table for causes of death other than malaria, Kassena-Nankana District, Ghana, 1995

\begin{tabular}{|c|c|c|c|c|c|c|c|c|c|c|c|c|c|}
\hline $\operatorname{Age} x$ & $\mathbf{I}_{\mathbf{x}}$ & ${ }_{n} p_{x}$ & $\mathbf{R}^{- \text {malaria }}$ & $\mathbf{p}^{\text {-malaria }}$ & $\mathbf{I}_{x}^{- \text {malaria }}$ & ${ }_{\mathrm{n}} \mathbf{q}_{\mathrm{x}}{ }^{- \text {malaria }}$ & ${ }_{n} d_{x}^{- \text {-malaria }}$ & ${ }_{\mathrm{n}} \mathbf{q}_{\mathrm{x} / \mathrm{n}} \mathbf{q}_{\mathrm{x}}{ }^{- \text {malaria }}$ & ${ }_{n} \mathbf{a}_{\mathbf{x}}^{- \text {malaria }}$ & ${ }_{n} \mathbf{m}_{x}^{- \text {-malaria }}$ & ${ }_{n} \mathbf{L}_{\mathbf{x}}^{- \text {-malaria }}$ & $\mathbf{T}_{\mathbf{x}}^{- \text {malaria }}$ & $\mathbf{e}_{\mathrm{x}}^{- \text {malaria }}$ \\
\hline $1-4$ & 91,349 & 0.9029 & 0.6615 & 0.9347 & 93,067 & 0.0653 & 6,081 & 1.486 & 1.856 & 0.0169 & 35,9228 & $5,393,824$ & 57.96 \\
\hline $10-14$ & 80,474 & 0.9833 & 0.7368 & 0.9877 & 85,318 & 0.0123 & 1,052 & 1.354 & 2.315 & 0.0025 & 42,3765 & $4,603,849$ & 53.96 \\
\hline 15-19 & 79,131 & 0.9872 & 0.6774 & 0.9913 & 84,266 & 0.0087 & 734 & 1.473 & 2.671 & 0.0017 & 41,9620 & $4,180,085$ & 49.61 \\
\hline $20-24$ & 78,115 & 0.9775 & 0.8788 & 0.9802 & 83,532 & 0.0198 & 1,655 & 1.136 & 2.726 & 0.0040 & 41,3896 & $3,760,464$ & 45.02 \\
\hline $35-39$ & 70,768 & 0.9495 & 0.8219 & 0.9583 & 76,772 & 0.0417 & 3,200 & 1.211 & 2.563 & 0.0085 & 37,6064 & $2,552,876$ & 33.25 \\
\hline $40-44$ & 67,196 & 0.9422 & 0.8308 & 0.9518 & 73,572 & 0.0482 & 3,549 & 1.198 & 2.580 & 0.0099 & 35,9271 & $2,176,812$ & 29.59 \\
\hline $45-49$ & 63,313 & 0.9199 & 0.8061 & 0.9349 & 70,023 & 0.0651 & 4,558 & 1.231 & 2.575 & 0.0134 & 33,9063 & $1,817,541$ & 25.96 \\
\hline $50-54$ & 58,241 & 0.9072 & 0.8482 & 0.9207 & 65,465 & 0.0793 & 5,192 & 1.170 & 2.595 & 0.0165 & 31,4836 & $1,478,479$ & 22.58 \\
\hline $55-59$ & 52,835 & 0.8443 & 0.7202 & 0.8852 & 60,273 & 0.1148 & 6,919 & 1.357 & 2.582 & 0.0244 & 28,4634 & $1,163,643$ & 19.31 \\
\hline
\end{tabular}

Note: $\mathrm{R}^{\text {-malaria }}=$ the proportion of deaths due to all causes other than malaria. All other functions are defined as in Table 1, but in this case refer to causes other than malaria. 
Table 3 Decomposition of estimated changes in life expectancy at birth if malaria were eliminated as a cause of death, by age group, Kassena-Nankana District, Ghana, 1995

\begin{tabular}{|c|c|c|c|c|c|c|c|c|}
\hline Age group & $\mathbf{L x}$ & ${ }_{n} \mathbf{L}_{\mathbf{x}}$ & $\mathbf{T}_{\mathbf{x}}$ & $\mathbf{l}_{\mathrm{x}}^{- \text {malaria }}$ & ${ }_{n} \mathbf{L}_{\mathbf{x}}^{- \text {malaria }}$ & $\mathbf{T}_{\mathbf{x}}^{- \text {malaria }}$ & Change & Percent \\
\hline 0 & 100,000 & 94,290 & $4,875,779$ & 100,000 & 96,491 & 5490,315 & 1.017 & 16.6 \\
\hline $1-4$ & 91,349 & 346,540 & $4,781,489$ & 93,067 & 359,228 & 5393,824 & 1.740 & 28.3 \\
\hline $5-9$ & 82,478 & 407,361 & $4,434,949$ & 86,986 & 430,746 & 5034,596 & 0.239 & 3.9 \\
\hline $10-14$ & 80,474 & 398,807 & $4,027,587$ & 85,318 & 423,765 & 4603,849 & 0.183 & 3.0 \\
\hline $15-19$ & 79,131 & 393,202 & $3,628,780$ & 84,266 & 419,620 & 4180,085 & 0.155 & 2.5 \\
\hline $20-24$ & 78,115 & 386,570 & $3,235,578$ & 83,532 & 413,896 & 3760,464 & 0.091 & 1.5 \\
\hline $25-29$ & 76,357 & 374,768 & $2,849,008$ & 81,877 & 403,253 & 3346,568 & 0.208 & 3.4 \\
\hline $30-34$ & 73,472 & 360,744 & $2,474,240$ & 79,347 & 390,439 & 2943,315 & 0.114 & 1.9 \\
\hline $35-39$ & 70,768 & 345,155 & $2,113,496$ & 76,772 & 376,064 & 2552,876 & 0.199 & 3.2 \\
\hline $40-44$ & 67,196 & 326,585 & $1,768,341$ & 73,572 & 359,271 & 2176,812 & 0.182 & 3.0 \\
\hline $45-49$ & 63,313 & 304,204 & $1,441,756$ & 70,023 & 339,063 & 1817,541 & 0.238 & 3.9 \\
\hline $50-54$ & 58,241 & 278,352 & $1,137,552$ & 65,465 & 314,836 & 1478,479 & 0.169 & 2.8 \\
\hline $55-59$ & 52,835 & 243,024 & 859,200 & 60,273 & 284,634 & 1163,643 & 0.421 & 6.9 \\
\hline $60-64$ & 44,607 & 202,955 & 616,175 & 53,354 & 247,572 & 879,009 & 0.202 & 3.3 \\
\hline $65-69$ & 36,824 & 156,935 & 413,221 & 45,440 & 203,090 & 631,437 & 0.367 & 6.0 \\
\hline $70-74$ & 26,514 & 111,232 & 256,286 & 35,703 & 154,846 & 428,347 & 0.175 & 2.9 \\
\hline $75+$ & 18,464 & 145,054 & 145,054 & 26,673 & 273,501 & 273,501 & 0.443 & 7.2 \\
\hline Total & - & - & - & - & - & - & 6.145 & 100.0 \\
\hline
\end{tabular}

$=$ Not applicable.

Note: Functions are defined as in Table 1. 
Figure 1 Diagnosed causes of death among children, Kassena-Nankana District, Ghana, 1995

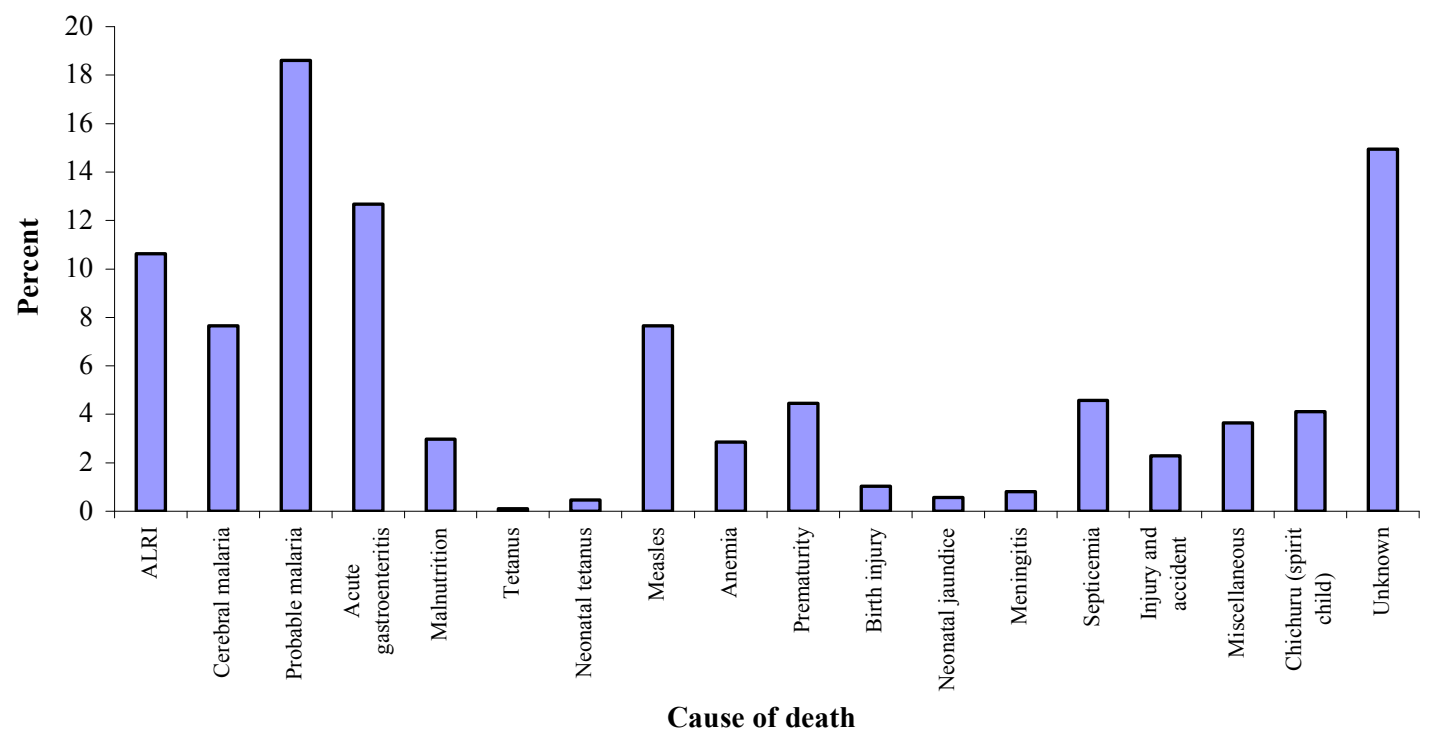

ALRI $=$ Acute lower respiratory infection. $\quad$ Chichuru $=$ Child with congenital problems considered as deviant and killed.

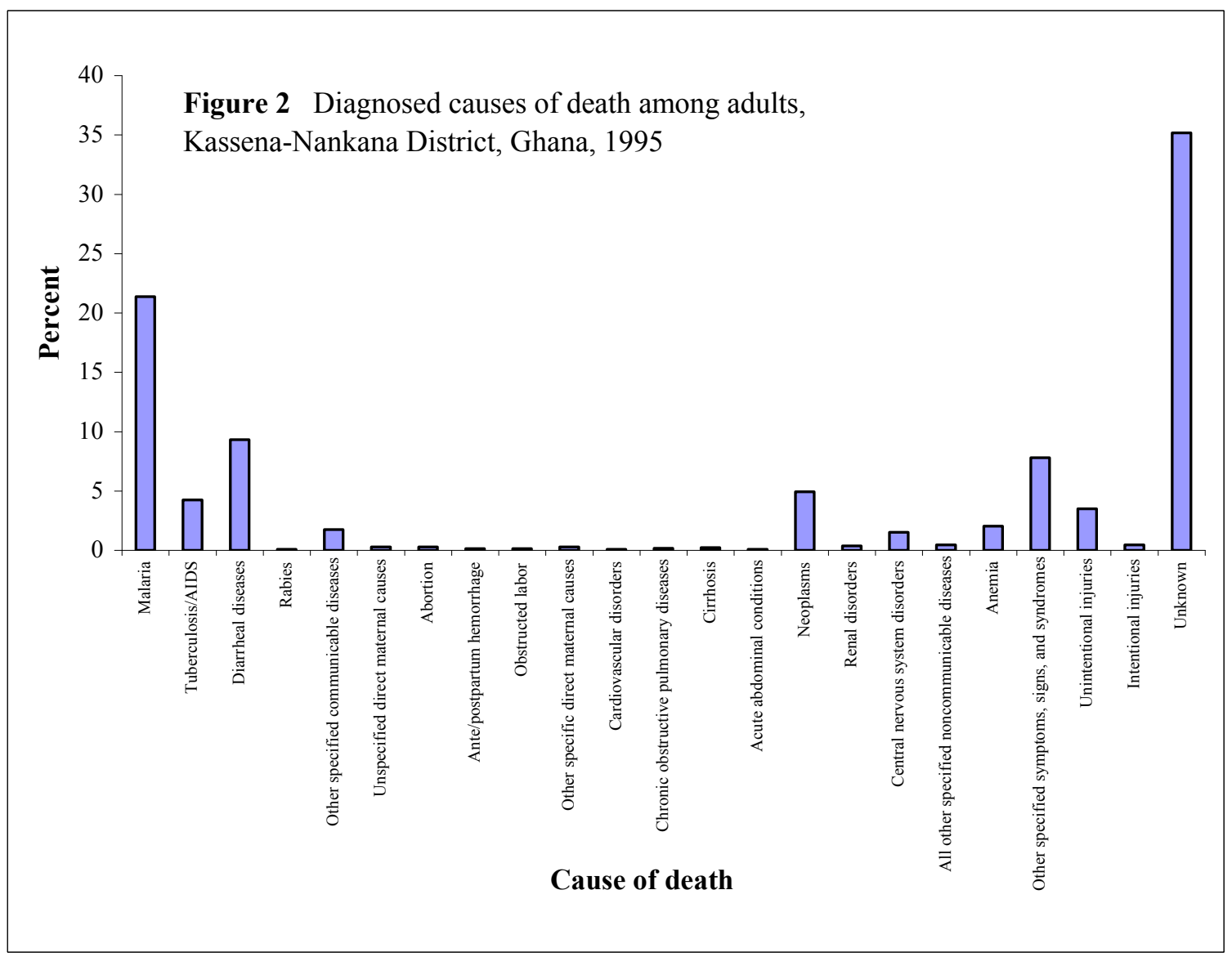




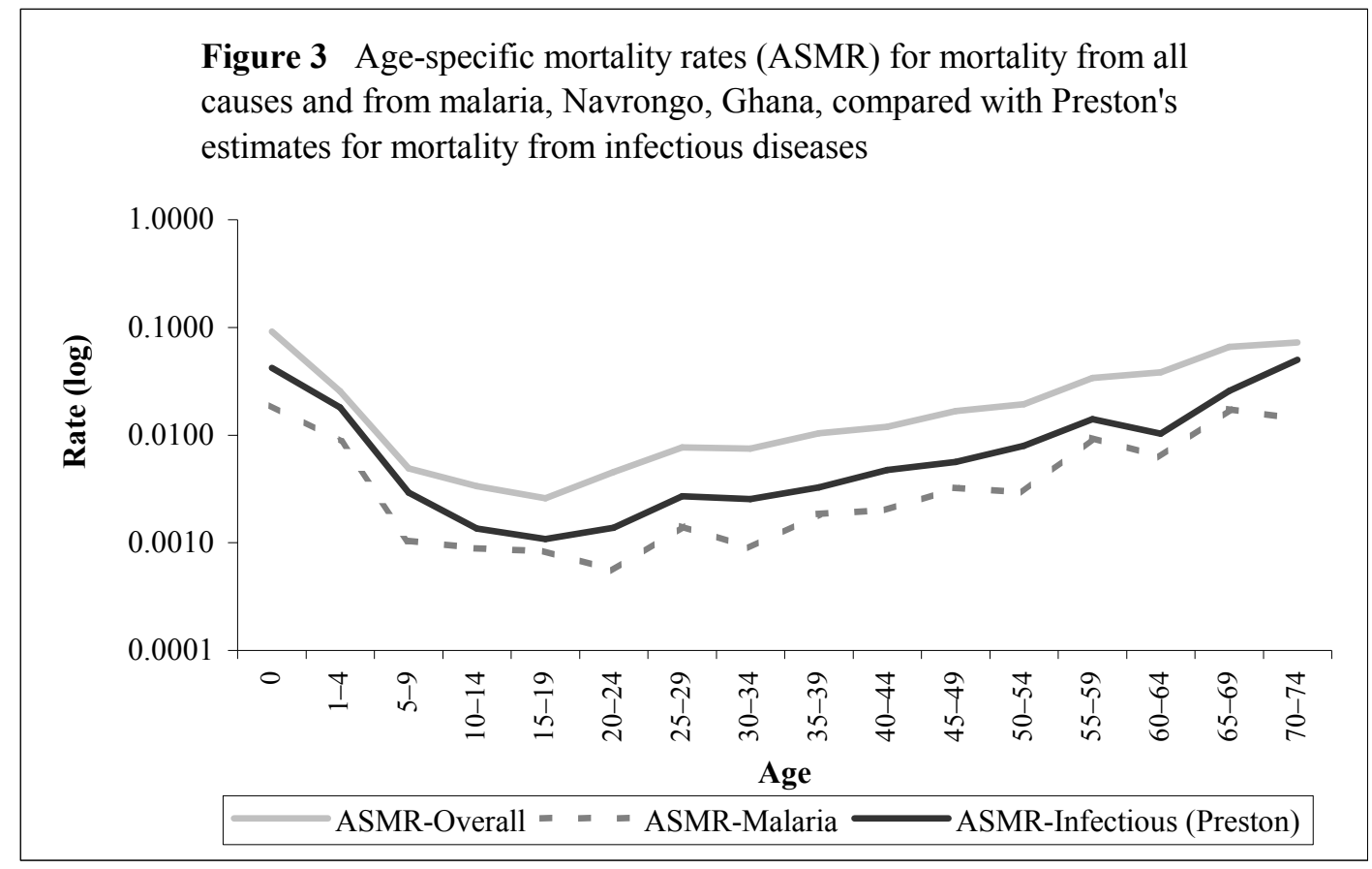

Figure 4 Comparison of estimated life expectancy for each age group without malaria, Kassena-Nankana District, Ghana

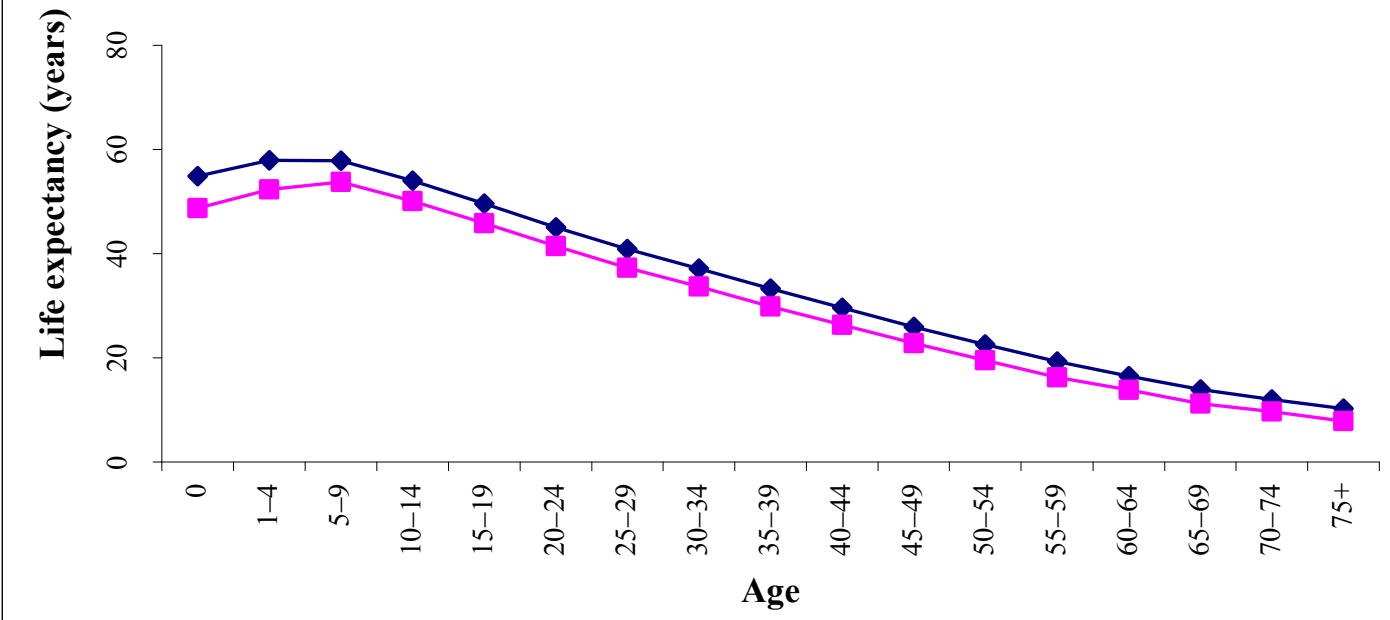

Without malaria - Overall 


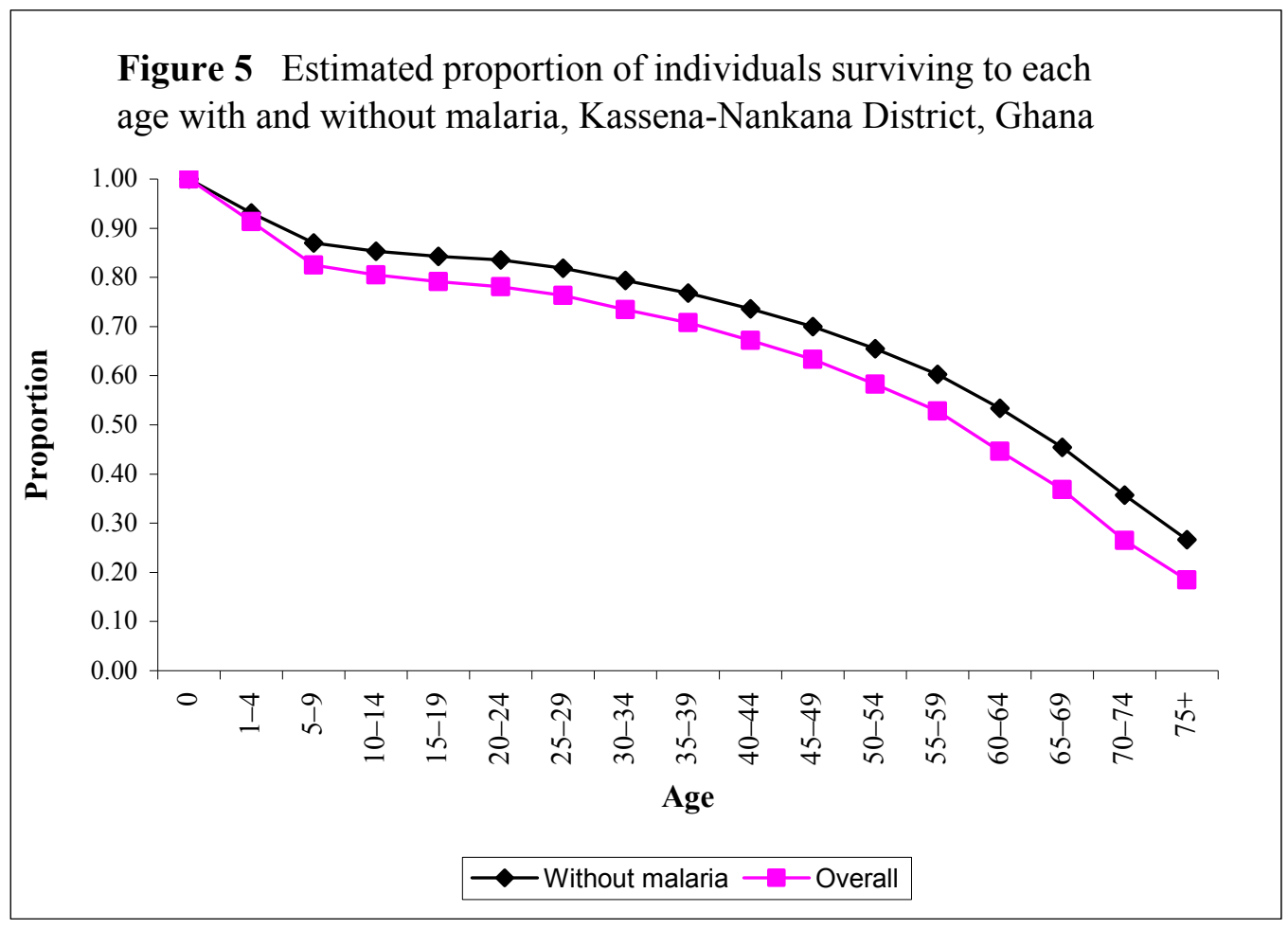




\section{APPENDIX 1}

In the analysis of causes of death, the force of the mortality function from different causes is additive because disentangling precisely the effects of other causes of death is difficult, particularly in settings where precise measurement is not possible. Thus, the sum of the different causes is equal to all causes combined as represented in equation (1) thus:

$$
\mu(x)=\sum_{i=1}^{I} \mu_{i}(x)
$$

where $\mu(x)$ is the force of mortality from all causes combined and parameters $\mu_{i}(x)$ refer to the death rate for the $i$ th cause of death. This implies that the rates of decrements are also additive:

$$
{ }_{n} m_{x}=\sum_{i=1}^{i}{ }_{n} m_{x i}
$$

where ${ }_{n} m_{x}$ is the rate of decrement from all causes and ${ }_{n} m_{x i}$ in this case is the rate of decrement from malaria.

In light of the basic relationship between mortality rates $\left({ }_{n} m_{x}\right)$ and the probability of dying $\left({ }_{n} q_{x}\right)$ as shown in the conventional life table, the transformation of the rates to probabilities of dying is shown in the following equation as:

$$
{ }_{n} q_{x}=\frac{n_{\cdot n} m_{x}}{1+\left(n-{ }_{n} a_{x}\right)_{n} m_{x}}
$$

where ${ }_{n} a_{x}$ is defined as the average number of person-years lived in the interval $x$ to $x+n$ by those who died in the interval. This relationship extends to multiple-decrement processes as follows:

$$
{ }_{n} q_{x i}=\frac{n \cdot{ }_{n} m_{x i}}{1+\left(n-{ }_{n} a_{x}\right)\left({ }_{n} m_{x i}+{ }_{n} m_{x,-i}\right)},
$$

where ${ }_{n} m_{x i}$ and ${ }_{n} m_{x,-i}$ represent decrement rates from malaria and all other causes other than malaria combined, respectively. Data concerning the causes of death by age and the corresponding number of person-years by the same subcategories define the probabilities of dying at each age $\left({ }_{n} q_{x}\right)$, by cause of death. Unfortunately, obtaining the ${ }_{n} a_{x}$ values is often difficult. We employed different techniques to estimate the ${ }_{n} a_{x}$ values. We assumed, first, that those who died in the interval on average lived halfway through the interval. On the basis of this assumption, we adopted an initial value of 2.5 for all age groups with an interval of five years. For the younger than one-year and one-to-four-year age groups, we adopted the procedure suggested by Coale and Demeny (1983). 
Using the ${ }_{n} a_{x}$ values of 2.5 in the ${ }_{n} m_{x} \rightarrow_{n} q_{x}$ conversion formula, we first estimate ${ }_{n} q_{x}$ values and use these to obtain ${ }_{n} d_{x}$ (the number of deaths between age $x$ and $x+n$ ) in a life table. These ${ }_{n} d_{x}$ estimates are plugged into the iteration formula below to obtain new sets of ${ }_{n} a_{x}$ values. These values are subsequently reintroduced into the ${ }_{n} m_{x} \rightarrow_{n} q_{x}$ conversion formula to re-estimate new ${ }_{n} d_{x}$ values, which are reintroduced in the iteration formula to obtain a new set of ${ }_{n} a_{x}$ values. This process is repeated until stable estimates of ${ }_{n} a_{x}$ are achieved (Preston et al. 2001). The iteration equation used is specified as follows:

$$
{ }_{n} a_{x}=\frac{-\frac{n}{24}{ }^{n} d_{x-n}+\frac{n}{2}{ }^{n} d_{x}+\frac{n}{24}{ }^{n} d_{x+n}}{{ }_{n} d_{x}} .
$$

The stable ${ }_{n} a_{x}$ values then are used to generate a life table for Kassena-Nankana District through the basic ${ }_{n} m_{x} \rightarrow_{n} q_{x}$ conversion formula. With the overall life table generated, we can estimate the probability of dying from malaria $\left.{ }_{n} q_{x}{ }^{i}\right)$, by applying the proportion of deaths that are due to malaria to the overall probabilities of dying for each age, ${ }_{n} q_{x}$, as follows:

$$
{ }_{n} q_{x i}={ }_{n} q_{x} \cdot \frac{{ }_{n} D_{x i}}{{ }_{n} D_{x}},
$$

where ${ }_{n} q_{x i}$ and ${ }_{n} D_{x i}$ represent the probability of dying from malaria and the observed number of deaths from malaria, respectively. The above relationship is based on the assumption that the observed death rates for malaria $\left.{ }_{n} M_{x i}\right)$ are equal to the life-table death rates for malaria $\left({ }_{n} m_{x i}\right)$, that is, ${ }_{n} M_{x i}={ }_{n} m_{x i}$.

Estimating the contribution of mortality from malaria to overall mortality also permits us to estimate the effect of completely eliminating malaria through "causedeleted" life-table analysis (Chiang 1968). If malaria were eliminated as a cause of death, survival at age interval $x$ to $x+n$, will be represented as:

$$
{ }_{n} p_{x,-i}={ }_{n} p_{x}{ }^{\left(\frac{{ }_{n} D_{x i}}{{ }_{n} D_{x}}\right)} .
$$

The approach described above assumes that the force of mortality function from each cause is proportional to all causes combined in the interval $x$ to $x+n$ and constant throughout the interval (Keyfitz 1985; Preston et al. 2001). The ${ }_{n} a_{x}$ values for the associated single-decrement life table were obtained using the following formula for all age groups except the first two and the last:

$$
{ }_{n} a_{x,-i}=n+R^{i} \frac{{ }_{n} q_{x}}{{ }_{n} q_{x,-i}}\left({ }_{n} a_{x}-n\right),
$$

where ${ }_{n} a_{x,-i}$ refers to the average number of person-years lived by those dying in the interval from all causes other than malaria, and $R^{i}$ represents the proportion of deaths due to malaria. For the other age groups, the iteration procedure used for estimating the ${ }_{n} a_{x}$ values in the parent life table is used. 
Appendix Table A1 Percentage distribution of deaths, by cause and age group, Kassena-Nankana District, Ghana, 1995

\begin{tabular}{|c|c|c|c|c|c|c|c|c|c|c|c|c|c|c|c|c|c|c|}
\hline \multirow[b]{2}{*}{ Cause of death } & \multicolumn{16}{|c|}{ Age group } & \multirow[b]{2}{*}{$(\mathbf{N})$} & \multirow{2}{*}{$\begin{array}{l}\text { Per- } \\
\text { cent }\end{array}$} \\
\hline & $<1$ & 1-4 & 5-9 & 10-14 & 15-19 & $20-24$ & 25-29 & 30-34 & 35-39 & $40-44$ & 45-49 & $50-54$ & 55-59 & $60-64$ & $65-69$ & 70+ & & \\
\hline \multicolumn{19}{|l|}{$\begin{array}{l}\text { Communicable, } \\
\text { maternal, perinatal, } \\
\text { and nutritional } \\
\text { conditions }\end{array}$} \\
\hline Perinatal conditions & 12.6 & 0.0 & 1.1 & 0.0 & 0.0 & 0.0 & 0.0 & 0.0 & 0.0 & 0.0 & 0.0 & 0.0 & 0.0 & 0.0 & 0.0 & 0.0 & $(48)$ & 2.2 \\
\hline $\begin{array}{l}\text { Infections and } \\
\text { parasitic diseases }\end{array}$ & 40.6 & 70.8 & 59.6 & 40.4 & 41.9 & 30.3 & 35.2 & 34.0 & 31.5 & 40.0 & 33.3 & 41.1 & 41.7 & 26.8 & 39.3 & 37.5 & $(975)$ & 44.4 \\
\hline $\begin{array}{l}\text { Respiratory } \\
\text { infections }\end{array}$ & 12.3 & 10.7 & 4.3 & 3.5 & 0.0 & 0.0 & 0.0 & 0.0 & 0.0 & 0.0 & 0.0 & 0.0 & 0.0 & 0.0 & 0.0 & 0.0 & (93) & 4.2 \\
\hline Maternal causes & 0.0 & 0.0 & 0.0 & 0.0 & 3.2 & 6.1 & 3.7 & 6.0 & 5.5 & 3.1 & 2.0 & 0.0 & 0.0 & 0.0 & 0.0 & 0.0 & (16) & 0.7 \\
\hline Malnutrition & 3.5 & 2.6 & 1.1 & 3.5 & 0.0 & 0.0 & 0.0 & 0.0 & 0.0 & 0.0 & 0.0 & 0.0 & 0.0 & 0.0 & 0.0 & 0.0 & $(26)$ & 1.2 \\
\hline \multicolumn{19}{|l|}{$\begin{array}{l}\text { Noncommunicable } \\
\text { diseases }\end{array}$} \\
\hline Neoplasms & 0.0 & 0.0 & 0.0 & 0.0 & 0.0 & 0.0 & 0.0 & 0.0 & 1.4 & 0.0 & 1.0 & 1.8 & 0.6 & 0.0 & 0.0 & 0.0 & (5) & 0.2 \\
\hline $\begin{array}{l}\text { Cardiovascular } \\
\text { diseases }\end{array}$ & 0.0 & 0.0 & 0.0 & 0.0 & 3.2 & 0.0 & 1.9 & 0.0 & 0.0 & 0.0 & 1.0 & 1.8 & 4.8 & 6.5 & 4.1 & 4.6 & $(42)$ & 1.9 \\
\hline Other & 0.0 & 0.0 & 0.0 & 5.3 & 0.0 & 9.1 & 14.8 & 14.0 & 8.2 & 10.8 & 8.1 & 8.9 & 8.3 & 11.4 & 9.8 & 8.5 & (123) & 5.6 \\
\hline Injury & 0.3 & 1.0 & 10.6 & 12.3 & 6.5 & 12.1 & 3.7 & 12.0 & 6.8 & 7.7 & 4.0 & 3.6 & 3.0 & 0.8 & 2.3 & 2.6 & (72) & 3.3 \\
\hline Unknown / others & 30.7 & 14.8 & 23.4 & 35.1 & 45.2 & 42.2 & 40.7 & 34.0 & 46.6 & 38.5 & 50.5 & 42.9 & 41.7 & 54.5 & 44.5 & 46.7 & (794) & 36.2 \\
\hline$(\mathrm{N})$ & $(374)$ & $(384)$ & (94) & $(57)$ & $(31)$ & (33) & (54) & $(50)$ & (73) & $(65)$ & (99) & $(112)$ & $(168)$ & $(123)$ & $(173)$ & $(304)$ & $(2,193)$ & - \\
\hline Percent & 100.0 & 100.0 & 100.0 & 100.0 & 100.0 & 100.0 & 100.0 & 100.0 & 100.0 & 100.0 & 100.0 & 100.0 & 100.0 & 100.0 & 100.0 & 100.0 & - & 100.0 \\
\hline
\end{tabular}

$-=$ Not applicable. 
Appendix Table A2 Number of deaths, by cause, after allocation of the unknown causes of death, Kassena-Nankana District, Ghana, 1995

\begin{tabular}{|c|c|c|c|c|c|c|c|c|c|c|c|c|c|c|c|c|c|c|}
\hline \multirow[b]{2}{*}{ Cause of death } & \multicolumn{16}{|c|}{ Age group } & \multirow[b]{2}{*}{$(\mathrm{N})$} & \multirow{2}{*}{$\begin{array}{l}\text { Per- } \\
\text { cent }\end{array}$} \\
\hline & $<1$ & $1-4$ & 5-9 & $10-14$ & $15-19$ & $20-24$ & 25-29 & $30-34$ & 35-39 & $40-44$ & $45-49$ & $50-55$ & $55-59$ & $60-66$ & 6 65-69 & $70+$ & & \\
\hline \multicolumn{19}{|l|}{$\begin{array}{l}\text { Communicable, maternal, } \\
\text { perinatal, and nutritional } \\
\text { conditions }\end{array}$} \\
\hline Perinatal conditions & 68 & 0 & 1 & 0 & 0 & 0 & 0 & 0 & 0 & 0 & 0 & 0 & 0 & 0 & 0 & 0 & 69 & 3.2 \\
\hline $\begin{array}{l}\text { Infectious and parasitic } \\
\text { diseases }\end{array}$ & 219 & 319 & 73 & 35 & 24 & 17 & 32 & 26 & 43 & 42 & 67 & 81 & 120 & 72 & 123 & 214 & $(1,508)$ & 68.7 \\
\hline Respiratory infections & 66 & 48 & 5 & 3 & 0 & 0 & 0 & 0 & 0 & 0 & 0 & 0 & 0 & 0 & 0 & 0 & (123) & 5.6 \\
\hline Maternal causes & 0 & 0 & 0 & 0 & 2 & 3 & 3 & 5 & 7 & 3 & 4 & 0 & 0 & 0 & 0 & 0 & (28) & 1.3 \\
\hline Malnutrition & 19 & 12 & 1 & 3 & 0 & 0 & 0 & 0 & 0 & 0 & 0 & 0 & 0 & 0 & 0 & 0 & (35) & 1.6 \\
\hline \multicolumn{19}{|l|}{ Noncommunicable diseases } \\
\hline Neoplasms & 0 & 0 & 0 & 0 & 0 & 0 & 0 & 0 & 2 & 0 & 2 & 4 & 2 & 0 & 0 & 0 & (9) & 0.4 \\
\hline Cardiovascular diseases & 0 & 0 & 0 & 0 & 2 & 0 & 2 & 0 & 0 & 0 & 2 & 4 & 14 & 18 & 13 & 26 & (79) & 3.6 \\
\hline Other & 0 & 0 & 0 & 5 & 0 & 5 & 14 & 11 & 11 & 11 & 16 & 18 & 24 & 31 & 31 & 49 & (224) & 10.2 \\
\hline Injury & 1 & 5 & 13 & 11 & 4 & 7 & 3 & 9 & 9 & 8 & 8 & 7 & 9 & 2 & 7 & 15 & (119) & 5.4 \\
\hline$(\mathrm{N})$ & (373) & (384) & (93) & (57) & (32) & (33) & (54) & (51) & (72) & (64) & $(99)$ & $(114)$ & $(167)$ & $(123)$ & $(174)$ & $(304)$ & $(2,193)$ & - \\
\hline
\end{tabular}


Appendix Table A3 General and multiple-decrement life table after allocation of deaths from unknown causes, Kassena-Nankana District, Ghana, 1995

\begin{tabular}{|c|c|c|c|c|c|c|c|c|c|c|c|c|c|c|c|c|}
\hline Age $x$ & P-years & $\mathrm{D}^{\text {all }}$ & $D^{\text {malaria }}$ & ${ }_{n} \mathbf{a}_{x}$ & ${ }_{n} \mathbf{m}_{\mathbf{x}}$ & ${ }_{n} q_{x}$ & ${ }_{n} \mathbf{p}_{x}$ & $\mathbf{l}_{\mathrm{X}}$ & ${ }_{n} d_{x}$ & ${ }_{n} \mathbf{L}_{\mathbf{X}}$ & $\mathbf{T}_{\mathrm{X}}$ & $\mathbf{e}_{\mathbf{x}}$ & ${ }_{n} q_{x}^{\text {malaria }}$ & ${ }_{n} d_{x}{ }^{\text {malaria }}$ & $I_{x}^{\text {malaria }}$ & ${ }_{n} m_{x}{ }^{\text {malaria }}$ \\
\hline 0 & 42,076 & 374 & 103 & 0.3 & 0.092 & 0.087 & 0.913 & 100,000 & 8,651 & 94,290 & $4,875,779$ & 48.8 & 0.024 & 2,382 & 33,551 & 0.025 \\
\hline $1-4$ & 15,001 & 384 & 146 & 1.9 & 0.026 & 0.097 & 0.903 & 91,349 & 8,871 & 346,540 & $4,781,489$ & 52.3 & 0.037 & 3,373 & 31,168 & 0.010 \\
\hline $5-9$ & 19,106 & 94 & 25 & 2.5 & 0.005 & 0.024 & 0.976 & 82,478 & 2,004 & 407,361 & $4,434,949$ & 53.8 & 0.006 & 533 & 27,795 & 0.001 \\
\hline $10-14$ & 16,920 & 57 & 21 & 2.3 & 0.003 & 0.017 & 0.983 & 80,474 & 1,344 & 398,807 & $4,027,587$ & 50.0 & 0.006 & 495 & 27,262 & 0.001 \\
\hline $15-19$ & 12,004 & 31 & 15 & 2.6 & 0.003 & 0.013 & 0.987 & 79,131 & 1,015 & 393,202 & $3,628,780$ & 45.9 & 0.006 & 491 & 26,767 & 0.001 \\
\hline $20-24$ & 7,254 & 33 & 6 & 2.7 & 0.005 & 0.023 & 0.977 & 78,115 & 1,759 & 386,570 & $3,235,578$ & 41.4 & 0.004 & 320 & 26,276 & 0.001 \\
\hline $25-29$ & 7,015 & 54 & 15 & 2.6 & 0.008 & 0.038 & 0.962 & 76,357 & 2,885 & 374,768 & $2,849,008$ & 37.3 & 0.010 & 801 & 25,956 & 0.002 \\
\hline $30-34$ & 6,672 & 50 & 9 & 2.6 & 0.007 & 0.037 & 0.963 & 73,472 & 2,703 & 360,744 & $2,474,240$ & 33.7 & 0.007 & 487 & 25,155 & 0.001 \\
\hline $35-39$ & 7,052 & 73 & 22 & 2.6 & 0.010 & 0.050 & 0.950 & 70,768 & 3,573 & 345,155 & $2,113,496$ & 29.9 & 0.015 & 1,077 & 24,668 & 0.003 \\
\hline $40-44$ & 5,468 & 65 & 16 & 2.6 & 0.012 & 0.058 & 0.942 & 67,196 & 3,882 & 326,585 & $1,768,341$ & 26.3 & 0.014 & 956 & 23,592 & 0.003 \\
\hline $45-49$ & 5,878 & 98 & 33 & 2.6 & 0.017 & 0.080 & 0.920 & 63,313 & 5,072 & 304,204 & $1,441,756$ & 22.8 & 0.027 & 1,708 & 22,636 & 0.006 \\
\hline $50-54$ & 5,766 & 112 & 27 & 2.6 & 0.019 & 0.093 & 0.907 & 58,241 & 5,406 & 278,352 & $1,137,552$ & 19.5 & 0.022 & 1,303 & 20,928 & 0.005 \\
\hline $55-59$ & 4,962 & 168 & 70 & 2.4 & 0.034 & 0.156 & 0.844 & 52,835 & 8,228 & 243,024 & 859,200 & 16.3 & 0.065 & 3,428 & 19,625 & 0.014 \\
\hline $60-64$ & 3,207 & 123 & 38 & 2.4 & 0.038 & 0.174 & 0.826 & 44,607 & 7,783 & 202,955 & 616,175 & 13.8 & 0.054 & 2,404 & 16,196 & 0.012 \\
\hline $65-69$ & 2,633 & 173 & 71 & 2.4 & 0.066 & 0.280 & 0.720 & 36,824 & 10,310 & 156,935 & 413,221 & 11.2 & 0.115 & 4,231 & 13,792 & 0.027 \\
\hline $70-74$ & 1,423 & 103 & 33 & 2.3 & 0.072 & 0.304 & 0.696 & 26,514 & 8,050 & 111,232 & 256,286 & 9.7 & 0.097 & 2,579 & 9,560 & 0.023 \\
\hline $75+$ & 1,579 & 201 & 76 & 7.9 & 0.127 & 1.000 & 0.000 & 18,464 & 18,464 & 145,054 & 145,054 & 7.9 & 0.378 & 6,981 & 6,981 & 0.048 \\
\hline Total & 126,018 & 2,193 & - & - & - & - & - & - & - & - & - & - & - & 33,551 & 33,551 & - \\
\hline
\end{tabular}

$-=$ Not applicable.

Notes: $\mathrm{D}^{\text {all }}$ and $\mathrm{D}^{\text {malaria }}$ refer to deaths from all causes and malaria-specific deaths, respectively.

All other functions are defined as in Table 1. Those functions with "malaria" as superscript refer to malaria-specific cases. 
Appendix Table A4 Associated single-decrement life table for causes of death other than malaria after allocation of unknown causes, Kassena-Nankana District, Ghana, 1995

\begin{tabular}{|c|c|c|c|c|c|c|c|c|c|c|c|c|c|}
\hline Age $x$ & $\mathbf{l}_{\mathbf{x}}$ & ${ }_{n} p_{x}$ & $\mathbf{R}^{- \text {malaria }}$ & $\mathrm{p}^{\text {-malaria }}$ & $\mathbf{l}_{\mathrm{X}}^{\text {-malaria }}$ & ${ }_{n} q_{x}^{- \text {-malaria }}$ & ${ }_{n} d_{x}^{\text {-malaria }}$ & ${ }_{n} q_{x} /{ }_{n} q_{x}{ }^{- \text {malaria }}$ & ${ }_{n} \mathbf{a}_{x}^{- \text {malaria }}$ & ${ }_{n} m_{x}^{- \text {malaria }}$ & ${ }_{n} \mathbf{L}_{x}^{- \text {malaria }}$ & $\mathbf{T}_{\mathrm{x}}^{\text {-malaria }}$ & $\mathbf{e}_{x}^{- \text {malaria }}$ \\
\hline 0 & 100,000 & 0.913 & 0.725 & 0.937 & 100,000 & 0.063 & 6,346 & 1.36 & 0.5 & 0.066 & 96,792 & $5,821,706$ & 58.2 \\
\hline $1-4$ & 91,349 & 0.903 & 0.620 & 0.939 & 93,654 & 0.061 & 5,746 & 1.58 & 1.9 & 0.016 & 362,329 & $5,724,914$ & 61.1 \\
\hline $5-9$ & 82,478 & 0.976 & 0.734 & 0.982 & 87,908 & 0.018 & 1,573 & 1.36 & 2.5 & 0.004 & 435,597 & $5,362,585$ & 61.0 \\
\hline $10-14$ & 80,474 & 0.983 & 0.632 & 0.989 & 86,335 & 0.011 & 913 & 1.58 & 2.3 & 0.002 & 429,184 & $4,926,988$ & 57.1 \\
\hline $15-19$ & 79,131 & 0.987 & 0.516 & 0.993 & 85,422 & 0.007 & 568 & 1.93 & 2.7 & 0.001 & 425,828 & $4,497,804$ & 52.7 \\
\hline $20-24$ & 78,115 & 0.977 & 0.818 & 0.982 & 84,855 & 0.018 & 1,566 & 1.22 & 2.7 & 0.004 & 420,715 & $4,071,976$ & 48.0 \\
\hline $25-29$ & 76,357 & 0.962 & 0.722 & 0.973 & 83,288 & 0.027 & 2,285 & 1.38 & 2.6 & 0.006 & 410,914 & $3,651,261$ & 43.8 \\
\hline $30-34$ & 73,472 & 0.963 & 0.820 & 0.970 & 81,003 & 0.030 & 2,452 & 1.22 & 2.5 & 0.006 & 398,993 & $3,240,347$ & 40.0 \\
\hline $35-39$ & 70,768 & 0.950 & 0.699 & 0.964 & 78,551 & 0.036 & 2,792 & 1.42 & 2.6 & 0.007 & 385,957 & $2,841,354$ & 36.2 \\
\hline $40-44$ & 67,196 & 0.942 & 0.754 & 0.956 & 75,759 & 0.044 & 3,323 & 1.32 & 2.6 & 0.009 & 370,718 & $2,455,397$ & 32.4 \\
\hline $45-49$ & 63,313 & 0.920 & 0.663 & 0.946 & 72,436 & 0.054 & 3,903 & 1.49 & 2.6 & 0.011 & 352,746 & $2,084,679$ & 28.8 \\
\hline $50-54$ & 58,241 & 0.907 & 0.759 & 0.929 & 68,533 & 0.071 & 4,884 & 1.30 & 2.6 & 0.015 & 330,887 & $1,731,933$ & 25.3 \\
\hline $55-59$ & 52,835 & 0.844 & 0.583 & 0.906 & 63,649 & 0.094 & 5,985 & 1.66 & 2.6 & 0.020 & 303,754 & $1,401,046$ & 22.0 \\
\hline $60-64$ & 44,607 & 0.826 & 0.691 & 0.876 & 57,664 & 0.124 & 7,156 & 1.41 & 2.6 & 0.027 & 271,033 & $1,097,292$ & 19.0 \\
\hline $65-69$ & 36,824 & 0.720 & 0.590 & 0.824 & 50,507 & 0.176 & 8,893 & 1.59 & 2.5 & 0.039 & 230,704 & 826,259 & 16.4 \\
\hline $70-74$ & 26,514 & 0.696 & 0.680 & 0.782 & 41,614 & 0.218 & 9,073 & 1.39 & 2.4 & 0.049 & 184,462 & 595,555 & 14.3 \\
\hline $75+$ & 18,464 & 0.000 & 0.622 & 0.000 & 32,542 & 1.000 & 3,2542 & 1.00 & 12.6 & 0.079 & 411,093 & 411,093 & 12.6 \\
\hline
\end{tabular}

Note: All functions are defined as in Table 1. Those functions with "-malaria" as superscript refer to deaths due to causes other than malaria. 
Appendix Table A5 Decomposition of changes in life expectancy at birth after allocation of unknown deaths, by age group, Kassena-Nankana District, Ghana, 1995

\begin{tabular}{lrrrrrrrr}
\hline Age $\mathbf{x}$ & $\mathbf{I}_{\mathbf{x}}$ & ${ }_{\mathbf{n}} \mathbf{L}_{\mathbf{x}}$ & $\mathbf{T}_{\mathbf{x}}$ & $\mathbf{l}_{\mathbf{x}}^{\text {-malaria }}$ & ${ }_{\mathbf{n}} \mathbf{L}_{\mathbf{x}}^{\text {-malaria }}$ & $\mathbf{T}_{\mathbf{x}}^{\text {-malaria }}$ & Change & Percent \\
\hline 0 & 100,000 & 94,290 & $4,875,779$ & 100,000 & 96,792 & $5,821,706$ & 1.434 & 15.2 \\
$1-4$ & 91,349 & 346,540 & $4,781,489$ & 93,654 & 362,329 & $5,724,914$ & 2.061 & 21.8 \\
$5-9$ & 82,478 & 407,361 & $4,434,949$ & 87,908 & 435,597 & $5,362,585$ & 0.315 & 3.3 \\
$10-14$ & 80,474 & 398,807 & $4,027,587$ & 86,335 & 429,184 & $4,926,988$ & 0.272 & 2.9 \\
$15-19$ & 79,131 & 393,202 & $3,628,780$ & 85,422 & 425,828 & $4,497,804$ & 0.248 & 2.6 \\
$20-24$ & 78,115 & 386,570 & $3,235,578$ & 84,855 & 420,715 & $4,071,976$ & 0.146 & 1.5 \\
$25-29$ & 76,357 & 374,768 & $2,849,008$ & 83,288 & 410,914 & $3,651,261$ & 0.336 & 3.5 \\
$30-34$ & 73,472 & 360,744 & $2,474,240$ & 81,003 & 398,993 & $3,240,347$ & 0.185 & 2.0 \\
$35-39$ & 70,768 & 345,155 & $2,113,496$ & 78,551 & 385,957 & $2,841,354$ & 0.368 & 3.9 \\
$40-44$ & 67,196 & 326,585 & $1,768,341$ & 75,759 & 370,718 & $2,455,397$ & 0.291 & 3.1 \\
$45-49$ & 63,313 & 304,204 & $1,441,756$ & 72,436 & 352,746 & $2,084,679$ & 0.461 & 4.9 \\
$50-54$ & 58,241 & 278,352 & $1,137,552$ & 68,533 & 330,887 & $1,731,933$ & 0.305 & 3.2 \\
$55-59$ & 52,835 & 243,024 & 859,200 & 63,649 & 303,754 & $1,401,046$ & 0.712 & 7.5 \\
$60-64$ & 44,607 & 202,955 & 616,175 & 57,664 & 271,033 & $1,097,292$ & 0.435 & 4.6 \\
$65-69$ & 36,824 & 156,935 & 413,221 & 50,507 & 230,704 & 826,259 & 0.660 & 7.0 \\
$70-74$ & 26,514 & 111,232 & 256,286 & 41,614 & 184,462 & 595,555 & 0.350 & 3.7 \\
$75+$ & 18,464 & 145,054 & 145,054 & 32,542 & 411,093 & 411,093 & 0.882 & 9.3 \\
Total & - & - & - & - & - & & $\mathbf{9 . 4 5 9}$ & $\mathbf{1 0 0 . 0}$ \\
\hline
\end{tabular}

$-=$ Not applicable.

Notes: All functions are defined as in Table 1. Those functions with "-malaria" as superscript refer to deaths due to causes other than malaria. 

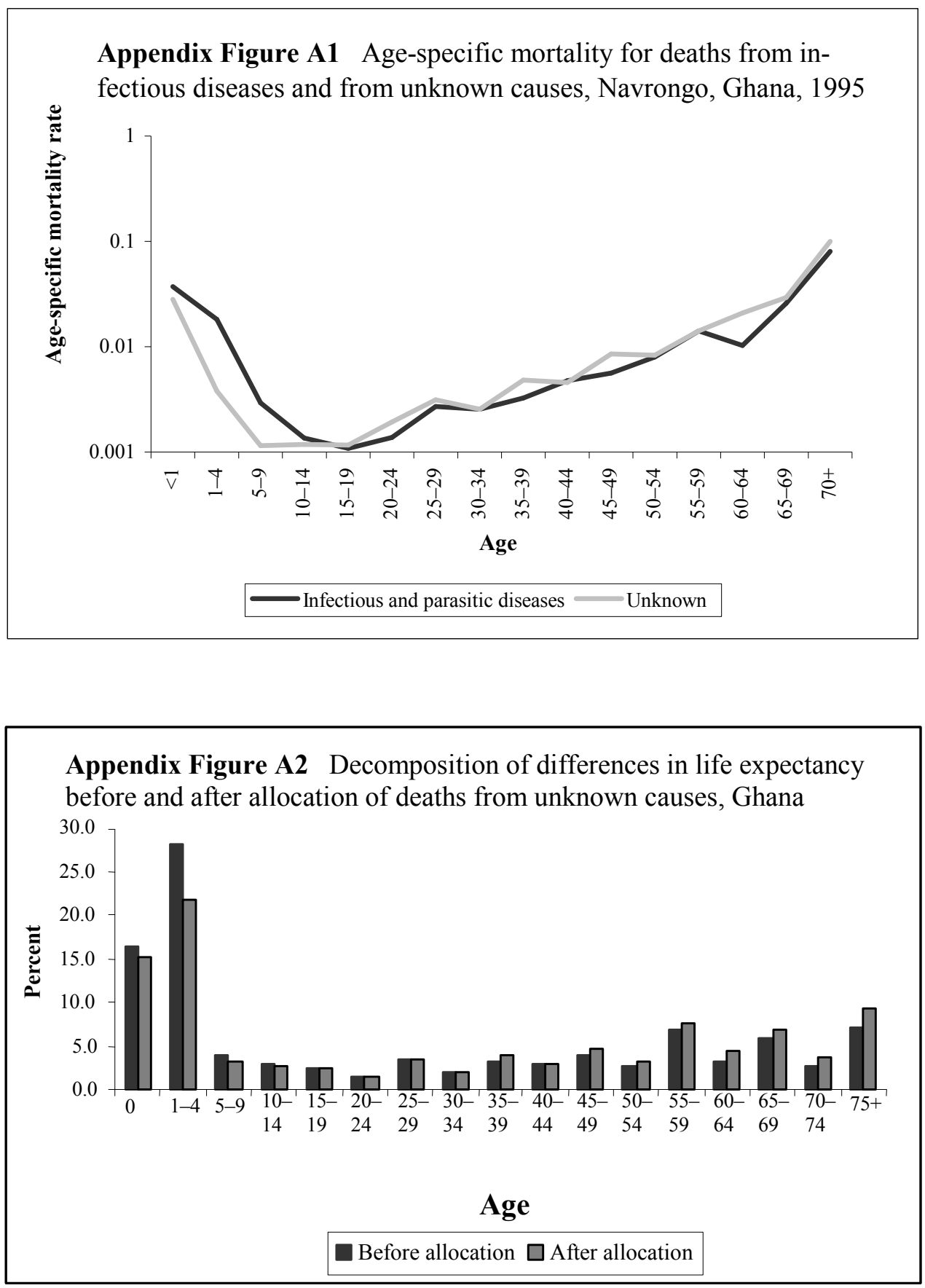


\section{POLICY RESEARCH DIVISION WORKING PAPERS}

If still in print, single copies of up to three working papers from 1989 through 2003 are available free of charge.

Beginning with the 2004 issues, working papers are no longer available in print format. Instead they are distributed electronically. As each new paper is completed subscribers are notified by e-mail and a link to the paper is provided.

To subscribe to the Policy Research Division working paper e-mail notification list, or to obtain back issues from 1989 to 2003, please send your request to prdwp@popcouncil.org.

PDFs of recent issues are available at www.popcouncil.org/publications/wp/prd/rdwplist.html

\section{5}

203

Ayaga A. Bawah and Fred N. Binka, "How many years of life could be saved if malaria were eliminated from a hyperendemic area of northern Ghana?"

202 Barbara S. Mensch, Susheela Singh, and John B. Casterline, "Trends in the timing of first marriage among men and women in the developing world."

201 Zachary Zimmer, "Active life expectancy and functional limitations among older Cambodians: Results from a 2004 survey."

200 Brian Wells Pence, Philomena Nyarko, James F. Phillips, and Cornelius Debpuur, "The effect of community nurses and health volunteers on child mortality: The Navrongo Community Health and Family Planning Project."

199 Zachary Zimmer, Linda G. Martin, Mary Beth Ofstedal, and Yi-Li Chuang, "Education of adult children and mortality of their elderly parents in Taiwan."
198 Mian Bazle Hossain, James F. Phillips, and Thomas K. LeGrand, "The impact of childhood mortality on fertility in six rural thanas of Bangladesh."

197 Kristine R. Baker, Mary Beth Ofstedal, Zachary Zimmer, Zhe Tang, and Yi-Li Chuang, "Reciprocal effects of health and economic well-being among older adults in Taiwan and Beijing."

196 Mark R. Montgomery and Paul C. Hewett, "Poverty and children's schooling in urban and rural Senegal.”

2004

195 Luciana Suran, Sajeda Amin, Lopita Huq, and Kobita Chowdury, "Does dowry improve life for brides? A test of the bequest theory of dowry in rural Bangadesh.” 
194 Barbara S. Mensch, Monica J. Grant, Mary P. Sebastian, Paul C. Hewett, and Dale Huntington. "The effect of a livelihoods intervention in an urban slum in India: Do vocational counseling and training alter the attitudes and behavior of adolescent girls?"

193 Amanda Ritchie, Cynthia B. Lloyd, and Monica Grant. "Gender differences in time use among adolescents in developing countries: Implications of rising school enrollment rates."

192 John Bongaarts. "Long-range trends in adult mortality: Models and projection methods."

191 John Koku Awoonor-Williams, Ellie S. Feinglass, Rachel Tobey, Maya N. Vaughan-Smith, Frank K. Nyonator, Tanya C. Jones, and James F. Phillips, "Bridging the gap between evidence-based innovation and national healthsector reform in Ghana."

190 Kelly Hallman, "Socioeconomic disadvantage and unsafe sexual behaviors among young women and men in South Africa."

189 Toshiko Kaneda, Zachary Zimmer, and Zhe Tang, "Differentials in life expectancy and active life expectancy by socioeconomic status among older adults in Beijing."

188 Cynthia B. Lloyd and Monica J. Grant, "Growing up in Pakistan: The separate experiences of males and females."
187 Zachary Zimmer, Xianghua Fang, Toshiko Kaneda, Zhe Tang, and Julia Kwong. "Trends and transitions in children's coresidence with older adults in Beijing municipality."

186 Sajeda Amin and Alaka M. Basu. "Popular perceptions of emerging influences on mortality and longevity in Bangladesh and West Bengal."

185 John Bongaarts. "Population aging and the rising cost of public pensions."

184 Mark R. Montgomery and Paul C. Hewett. "Urban poverty and health in developing countries: Household and neighborhood effects.

2003

183 Agnes R. Quisumbing and Kelly Hallman. "Marriage in transition: Evidence on age, education, and assets from six developing countries."

182 Paul C. Hewett, Barbara S. Mensch, and Annabel S. Erulkar, "Consistency in the reporting of sexual behavior among adolescent girls in Kenya: A comparison of interviewing methods."

181 Zachary Zimmer, Linda G. Martin, and Hui-Sheng Lin, "Determinants of old-age mortality in Taiwan." 
180 Frank K. Nyonator, J. Koku Awoonor-Williams, James F. Phillips, Tanya C. Jones, and Robert A. Miller, "The Ghana Community-based Health Planning and Services Initiative: Fostering evidence-based organizational change and development in a resourceconstrained setting."

179 John Bongaarts and Griffith Feeney, "Estimating mean lifetime."

178 Elizabeth F. Jackson, Patricia Akweongo, Evelyn Sakeah, Abraham Hodgson, Rofina Asuru, and James F. Phillips, "Women's denial of having experienced female genital cutting in northern Ghana: Explanatory factors and consequences for analysis of survey data."

177 John Bongaarts, "Completing the fertility transition in the developing world: The role of educational differences and fertility preferences."

176 Cynthia B. Lloyd and Paul C. Hewett, "Primary schooling in sub-Saharan Africa: Recent trends and current challenges."

175 James F. Phillips, Tanya C. Jones, Frank K. Nyonator, and Shruti Ravikumar, "Evidence-based development of health and family planning programs in Bangladesh and Ghana."

174 Geoffrey McNicoll, "Population and development: An introductory view."
173 Paul Demeny, "Population policy: A concise summary."

172 Zachary Zimmer, Napaporn Chayovan, Hui-Sheng Lin, and Josefina Natividad, "How indicators of socioeconomic status relate to physical functioning of older adults in three Asian societies."

171 Sajeda Amin and Nagah H. AlBassusi, "Wage work and marriage: Perspectives of Egyptian working women."

170 Ravai Marindo, Steve Pearson, and John B. Casterline, "Condom use and abstinence among unmarried young people in Zimbabwe: Which strategy, whose agenda?"

169 Zachary Zimmer and Julia Dayton, "The living arrangements of older adults in sub-Saharan Africa in a time of HIV/AIDS."

168 Paul C. Hewett, Annabel S. Erulkar, and Barbara S. Mensch, "The feasibility of computerassisted survey interviewing in Africa: Experience from two rural districts in Kenya." 